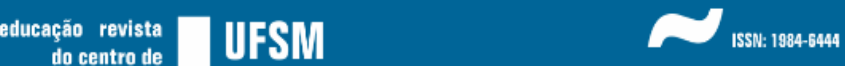

\section{Metacognição, programação de computadores e robótica: um mapeamento de teses em língua portuguesa no campo educacional}

\author{
Metacognição, computer programming and robotics: um mapping of \\ teses in Portuguese language not educational field
}

\section{Fernanda Batistela}

Doutoranda na Universidade de Passo Fundo. Passo Fundo, Rio Grande do Sul, Brasil. batistela.fernanda@gmail.com - https://orcid.org/0000-0002-5595-1626

\section{Adriano Canabarro Teixeira}

Professor doutor na Universidade de Passo Fundo. Passo Fundo, Rio Grande do Sul, Brasil. teixeira@upf.br - https://orcid.org/0000-0002-7941-3515

Cleci Teresinha Werner da Rosa

Professora doutora na Universidade de Passo Fundo. Passo Fundo, Rio Grande do Sul, Brasil. cwerner@upf.br - https://orcid.org/0000-0001-9933-8834

Recebido em 07 de janeiro de 2019

Aprovado em 09 de janeiro de 2019

Publicado em 05 de maio de 2021

\section{RESUMO}

Objetiva-se analisar que aspectos teóricos e práticos da metacognição, da programação de computadores e da robótica estão sendo abordados em teses produzidas em língua portuguesa no campo da Educação. À vista disso, procede-se a uma abordagem quali-quantitativa, exploratória, por meio de procedimentos predominantemente bibliográficos, do tipo estado do conhecimento. Para delimitação do corpus documental, filtraram-se as teses no período de 2013 a 2017, que constam no Catálogo de Teses e Dissertações da Capes, Programas de Pós-Graduação em Educação com nota 7 no sistema de Avaliação Capes, RCAAP e B-On. Em um processo de ruptura dos pré-conceitos, 57 pesquisas foram filtradas, resultando-se em 17 teses para analisá-las. Para isso, utilizaram-se três categorias gerais: programação de computadores, metacognição; scratch, metacognição; e robótica, metacognição. Além dessas, outras quatro específicas: programação de computadores; robótica; scratch; e metacognição. Em síntese, por meio da análise do título, das palavras-chave, do resumo e do sumário, 13 teses contemplaram as categorias, sendo três consideradas como gerais e que agregam as temáticas em investigação. O estudo associando tais temáticas revela-se incipiente, porém promissor, pois, diante das fontes pesquisadas, mostra carência de pesquisas nessa 


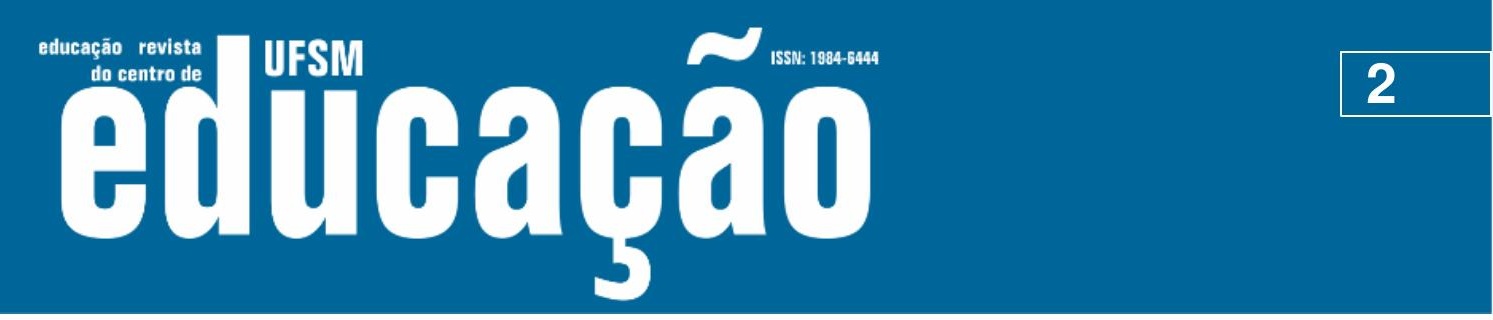

ISSN: 1984-6444 | http://dx.doi.org/10.5902/1984644440698

esfera. Por outro lado, possibilita a ampliação para um estado da arte que poderá validar o resultado obtido.

Palavras-chave: Metacognição; Programação de computadores; Robótica.

\section{ABSTRACT}

Objective-it will be analyzed that theoretical and practical aspects of metacognição, computer programming and robotics are being addressed in teses produced in Portuguese language not in the field of Education. In view of this, a quali-quantitative, exploratory approach is proceeded through predominantly bibliographic procedures, of the conhecimento status. For the delimitation of the documentary corpus, filters will be carried out in the period from 2013 to 2017, constants will not be included in the Catalog of Teses and Dissertações da Capes, Programs of Poster-Graduação em Educação with note 7, no system of Avaliação Capes, RCAAP and B-On. Num process of rupture of loans, 57 filtered foram investigations, resulting in 17 tests for analysis. For this, it uses three categories gerais: computer program, metacognição; scratch, metacognição; y Robotics, metacognição. Além dessas, outras quatro specific: computer programming; robotics; y scratch; metacognição. In this case, by way of an analysis of the title, you give chavras-chave, of the summary and of the sum, 13 theses contemplating the categories, being considered three as gerais and adding thematic subjects in research. Or I am associating these thematic ones, the promissor, pois, diante das fontes pesquisadas, shows the nature of research in this area. On the other hand, it allows an extension to a state of art that will be able to validate or result obtained.

Keywords: Metacognição; Computer Programming; Robotics

\section{Introdução}

Para o desenvolvimento de novas investigações, é imprescindível conhecer o que já foi produzido na área. Para isso, é fundamental visitar bancos de dados, periódicos e outros que permitam verificar os trabalhos já produzidos. Em Petersen (2008), um mapeamento sistemático tem como objetivos fornecer uma visão geral de uma determinada área, quantidade e tipos de pesquisas e os resultados disponíveis nelas. Esse exercício de mapear ou de encontrar e analisar estudos primários, relacionados com a questão de pesquisa, por meio de determinadas estratégias de busca, é visto na literatura como estudos secundários, de diferentes tipos, como: estado da arte, estado do conhecimento, estado da questão. 


\section{Aitloapẫ

ISSN: 1984-6444 | http://dx.doi.org/10.5902/1984644440698

classifica-se como do tipo estado da arte. Enquanto que, se a busca pretende identificar apenas um setor das publicações, por exemplo, uma determinada área do conhecimento, designa-se o tipo de estudo como estado do conhecimento.

Embora esses dois tipos de estudos apresentam-se de diferentes formas, eles possuem similaridades. Segundo Ferreira (2002), eles parecem comungar do desafio de mapeamento e discussão das produções encontradas. A intenção é descobrir seus aspectos e dimensões em destaque nas diversas épocas e lugares, em que formas e condições têm-se produzido dissertações e teses, publicações em periódicos e comunicações em congressos e seminários. Por fim, esses tipos de estudos apresentam metodologicamente um

\section{caráter inventariante e descritivo da produção acadêmica e científica sobre o tema que busca investigar, à luz de categorias e facetas que se caracterizam enquanto tais em cada trabalho e no conjunto deles, sob os quais o fenômeno passa a ser analisado" (FERREIRA, 2002, p. 258).}

Nóbrega-Therrien e Therrien (2004) apresentam o estado da questão, metodologia que, segundo Novaes (2017), vem sendo muito utilizada em pesquisas na Universidade Estadual do Ceará. Se comparado ao estado da arte ou do conhecimento, estes vão mapear e discutir uma produção contida em fontes de consulta disponíveis na literatura, o estado da questão vai realizar uma busca seletiva, crítica e substancial em fontes científicas ancoradas nas especificidades e nos interesses do próprio pesquisador. Esse tipo de estudo tem como finalidade, por meio de um rigoroso levantamento bibliográfico na consulta a documentos substanciais, levar o pesquisador a registrar o estado atual da ciência em relação ao objeto ou tema de sua investigação. É esse momento que resultará na definição da delimitação do problema de pesquisa, bem como seu objeto de investigação e objetivos da pesquisa.

Quanto à metodologia, cabe salientar que se encontram na literatura, estudos inicialmente usados nas áreas da medicina, identificados como Revisões Sistemáticas de Literatura (KITCHENHAM, 2004) e Mapeamento Sistemático (Systematic Mapping Study - SME) (PETERSEN ET AL, 2008, 2015), e que, a partir de seus resultados, despertaram o interesse de outras áreas, que passaram a adotar tais abordagens. 


\section{usm

ISSN: 1984-6444 | http://dx.doi.org/10.5902/1984644440698

conceitos, em que é afastada a pesquisa desse cotidiano, retirando-se a possibilidade das falsas evidências e permanecendo-se somente com os conceitos principais, que serão as categorias de análise. Tais categorias iniciam pelo que denominamos de Momento I, relacionado ao Catálogo de Teses e Dissertações, disponibilizado a partir de 2002 pela Capes.

\section{Momento I: Catálogo de Teses e Dissertações da Capes}

Uma vez sinalizados os termos de interesse dos pesquisadores, iniciou-se o processo de filtragem dos 35 descritores elencados. Ao refinar os resultados, obtiveram-se dez descritores e 49 teses, representadas no gráfico a seguir. Observase que 25 descritores foram eliminados pelo processo de filtragem ou por resultarem uma quantidade superior a 100 teses. Pode-se dizer que os descritores eliminados são, de acordo com Morosini (2015), vinculados a algumas das crenças e saberes pelo tema escolhido. 


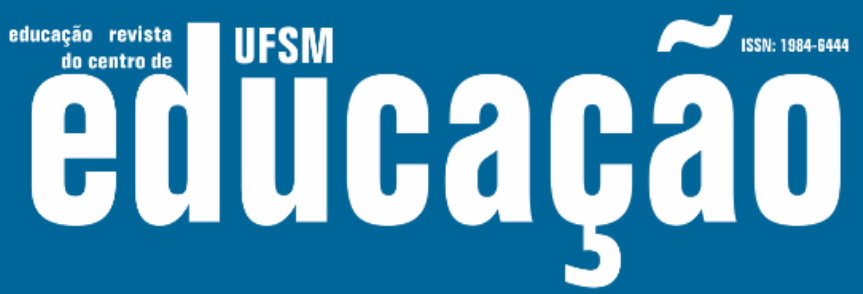

ISSN: 1984-6444 | http://dx.doi.org/10.5902/1984644440698

Gráfico 1 - Resultado do mapeamento no Catálogo de Teses e Dissertações da Capes

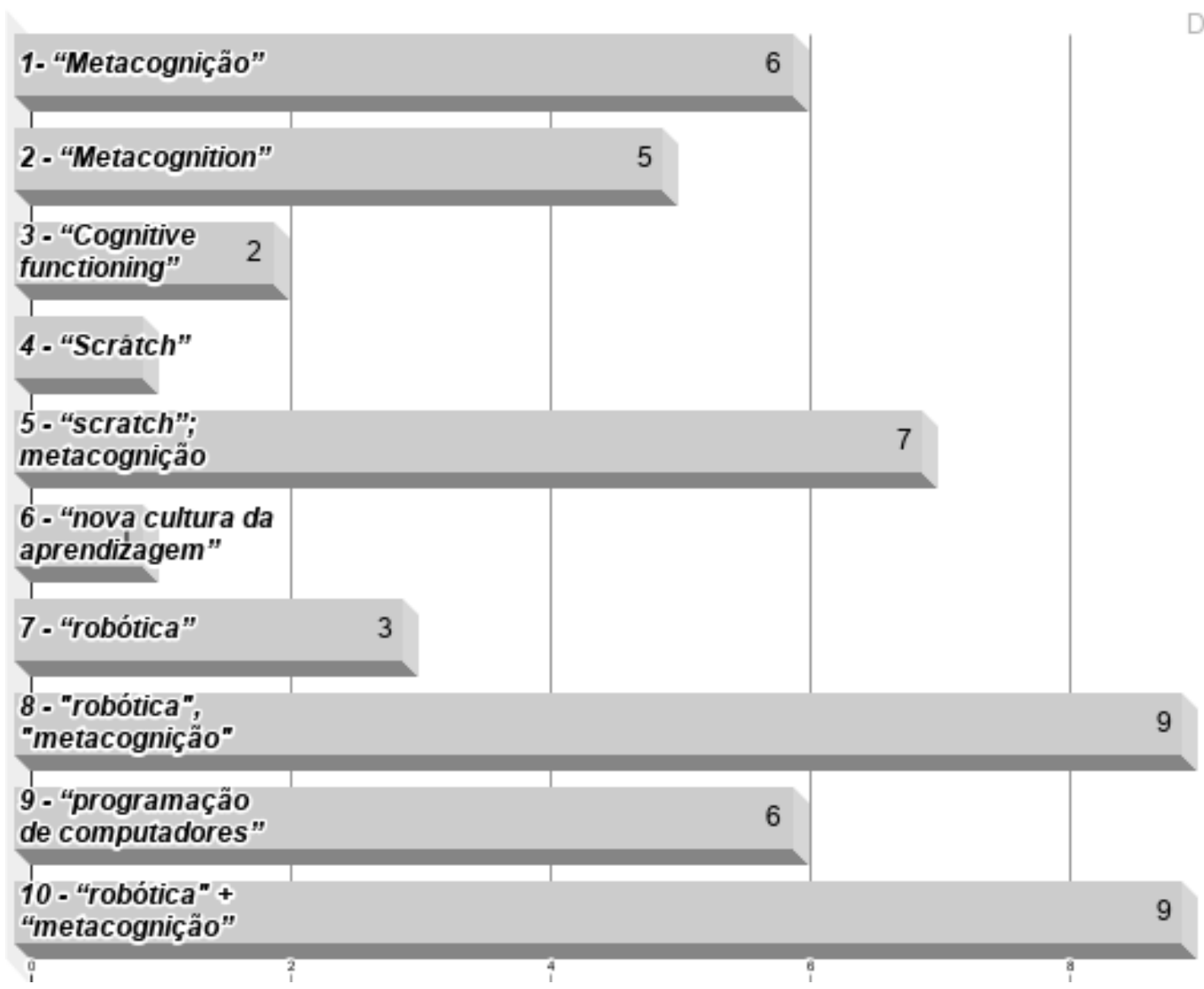

Fonte: os autores (2019).

Tais resultados são, segundo Messina (1999), um início do que identifica como mapa que conduzirá os pesquisadores a continuar caminhando em um processo de produção científica. Salienta-se que os dez descritores a que se refere serão utilizados nas próximas fontes de busca, caracterizando o que Morosini (2015) identifica a uma transformação do fato social em científico, em que o pesquisador se afasta do seu cotidiano e rompe com os seus pré-conceitos.

\section{Momento II: Programas de Pós-Graduação em Educação com nota 7}

Prosseguindo o mapeamento, segue-se por meio dos Programas de PósGraduação em Educação avaliados pela Capes na última quadrienal com nota 7. A 


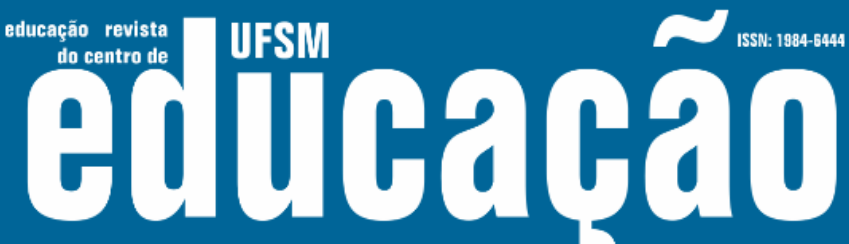

ISSN: 1984-6444 | http://dx.doi.org/10.5902/1984644440698

partir do acesso à Plataforma Sucupira, buscou-se por esses programas com os Cursos Avaliados e Reconhecidos pela Capes. Nesse sentido, nos dados quantitativos de programa Por Nota, ao acessar a Nota objetivada, optou-se pela Educação e, ao clicar na Área de Conhecimento pré-selecionada, o sistema apresentou a Universidade do Estado do Rio de Janeiro (UERJ), a Universidade do Vale do Rio dos Sinos (Unisinos) e a Universidade Federal de Minas Gerais (UFMG) como instituições que apresentam Programas de Pós-Graduação em Educação com Nota 7.

Esse segundo momento deteve-se aos dez descritores resultantes do Catálogo de Teses e Dissertações da Capes e nos mesmos filtros: tipo (doutorado), anos (2013 a 2017), Programa (Educação). A partir disso, conclui-se a inexistência de teses de doutorado nos três Programas, conforme explícito no quadro a seguir, que ilustra os achados dessa busca.

Quadro 2 - Resultados obtidos a partir dos Programas de Nota 7

\begin{tabular}{|c|c|c|c|}
\hline CATEGORIA & UERJ & UNISINOS & UFMG \\
\hline “Metacognição" & $\begin{array}{c}3 \text { dissertações } \\
(1997,1999 \\
2001)\end{array}$ & - & 2 teses (2004) e 1 Dissertação (2010) \\
\hline "Metacognition" & - & - & - \\
\hline "Cognitive functioning" & - & - & - \\
\hline "Scratch" & - & - & 1 dissertação (2012) \\
\hline "scratch"; metacognição & - & $\begin{array}{c}1 \\
\text { dissertação } \\
(2015)\end{array}$ & $\begin{array}{l}2 \text { teses }(2004) \text { e } 2 \text { dissertações } \\
(2004,2010,2012)\end{array}$ \\
\hline "nova cultura da aprendizagem" & - & - & - \\
\hline "Robótica" & - & - & - \\
\hline "robótica"; "metacognição" & - & - & 1 teses (2004) e 1 dissertação (2010) \\
\hline $\begin{array}{l}\text { "programação de computadores" } \\
\text { + "metacognição" }\end{array}$ & - & - & 2 teses (2004) e 1 dissertação (2010) \\
\hline "robótica" + "metacognição" & - & - & $\begin{array}{c}2 \text { teses (2004 e 2010) e } 1 \text { dissertação } \\
\text { (2004) }\end{array}$ \\
\hline
\end{tabular}

Fonte: os autores (2019). 


\section{Tisn ellitharao

ISSN: 1984-6444 | http://dx.doi.org/10.5902/1984644440698

se o momento seguinte associado ao que Romanowski (2002, p. 14) identifica como momento de organizar as informações existentes e de verificar quais dessas teses repetem-se para chegar a um balanço entre os resultados.

\section{O balanço dos resultados}

Com base no termo balanço dos resultados, apontam-se os enfoques do processo de ruptura dos pré-conceitos. Desse modo, objetiva-se organizar as informações orientando-se por facetas, conforme indicado por Ferreira (2002) e por modelos de análise, seguindo o anunciado por Morosini (2015). Ferreira (2002) defende que, nesse momento, é necessário encontrar nas pesquisas, as dimensões destaques sobre o tema que se busca investigar à luz das categorias e facetas a serem analisadas. Para isso, Morosini (2015) menciona que é necessário construir um modelo de análise, dividido em duas dimensões: organização situacional; especificidades. Tais dimensões representam, respectivamente, os referenciais teóricos e metodológicos sobre as pesquisas encontradas.

\section{Modelo I: Organização situacional das informações}

Dividiu-se a produção desse modelo de análise em duas perspectivas norteadoras. Na primeira, partindo-se das 57 pesquisas provenientes do processo de ruptura dos pré-conceitos, avaliando-se dois enfoques: a presença de teses repetidas quanto à presença das categorias gerais e específicas. A partir desse filtro, na segunda, responde-se a três perguntas: que teses apresentam os descritores no título, nas palavras-chave, no resumo, no sumário e/ou no abstract? São provenientes de quais universidades? Em que ano foram defendidas? Chegando-se, dessa forma, a uma visão geral das pesquisas alcançadas neste estudo.

\section{Primeira perspectiva situacional: balanço das teses repetidas}

Quanto à primeira perspectiva, criou-se a planilha <https://goo.gl/oV6Qvy> cujo procedimento é exemplificado no Quadro 3. Na planilha original, relacionaram-se as 57 teses de acordo com os sites de busca. Depois, as teses foram identificadas por 


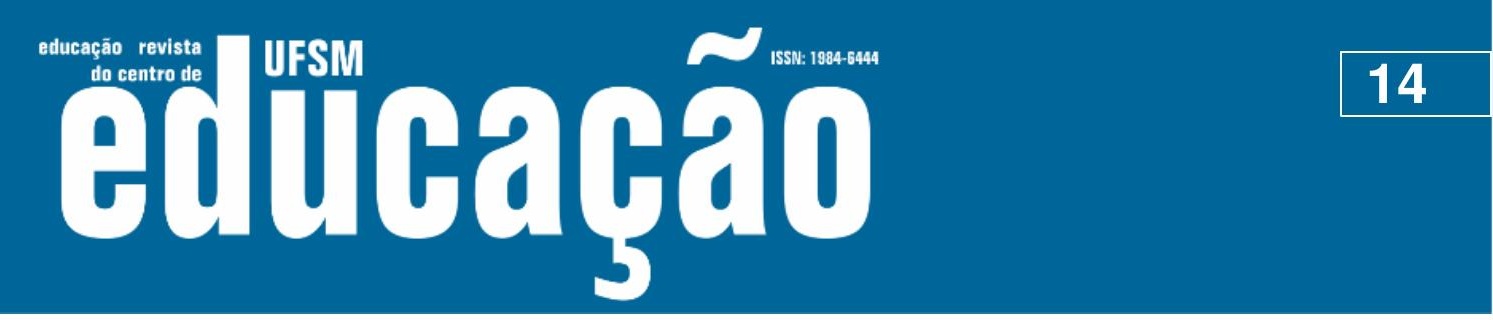

ISSN: 1984-6444 | http://dx.doi.org/10.5902/1984644440698

cores distintas, de acordo com os títulos repetidos, a fim de somá-las. Por exemplo, a pesquisa de Alcântara (2014), foi encontrada sete vezes por meio da busca nos sites, mas está sendo considerada apenas uma para o balanço dos resultados. Como resposta a essa análise, das 57 teses, consideraram-se 17 para serem analisadas sob a segunda perspectiva norteadora.

Quadro 3 - Exemplo do balanço das teses repetidas

\begin{tabular}{|c|c|c|c|c|c|}
\hline \multicolumn{2}{|c|}{$\begin{array}{l}\text { CATÁLOGO DE TESES E } \\
\text { DISSERTAÇÕES }\end{array}$} & \multicolumn{2}{|c|}{ RCAAP } & \multicolumn{2}{|c|}{ B-ON } \\
\hline $\begin{array}{l}\text { Metacognição ( } 6 \\
\text { resultados) }\end{array}$ & $\begin{array}{l}\text { "Metacognition" } \\
\text { (5 resultados) }\end{array}$ & $\begin{array}{l}\text { "Metacognição" } \\
\text { (2 resultados) }\end{array}$ & $\begin{array}{l}\text { "Robótica" } \\
\text { resultados) }\end{array}$ & $\begin{array}{l}\text { Metacognição } \\
\text { (2 resultado) }\end{array}$ & $\begin{array}{l}\text { "scratch"; } \\
\text { metacognição } \\
\text { (1 resultado) }\end{array}$ \\
\hline $\begin{array}{l}\text { ALCÂNTARA, } \\
\text { Marcelo Silveira } \\
\text { de. } \\
\text { Metacognição e } \\
\text { autorregulação } \\
\text { na graduação } \\
\text { universitária: } \\
\text { estratégias de } \\
\text { estudo individual } \\
\text { e ensino- } \\
\text { aprendizagem } \\
\text { em contexto de } \\
\text { iniciação à } \\
\text { expertise. [tese } \\
\text { de doutorado]. } \\
\text { Universidade } \\
\text { Católica de } \\
\text { Brasília, 2014. }\end{array}$ & $\begin{array}{l}\text { ROSÁRIA, } \\
\text { Helena Ruiz } \\
\text { Nakashima. A } \\
\text { dialética dos } \\
\text { conhecimentos } \\
\text { pedagógicos } \\
\text { dos conteúdos } \\
\text { tecnológicos e } \\
\text { suas } \\
\text { contribuições } \\
\text { para a ação } \\
\text { docente e para o } \\
\text { processo de } \\
\text { aprendizagem } \\
\text { apoiados por um } \\
\text { ambiente virtual. } \\
\text { tese de } \\
\text { doutorado]. } \\
\text { Universidade de } \\
\text { São Paulo, } \\
\text { 2014. Pal. }\end{array}$ & $\begin{array}{l}\text { ALCÂNTARA, } \\
\text { Marcelo Silveira } \\
\text { de. } \\
\text { Metacognição e } \\
\text { autorregulação } \\
\text { na graduação } \\
\text { universitária: } \\
\text { estratégias de } \\
\text { estudo } \\
\text { individual } \\
\text { ensino- } \\
\text { aprendizagem } \\
\text { em contexto de } \\
\text { iniciação à a } \\
\text { expertise. [tese } \\
\text { de doutorado]. } \\
\text { Universidade } \\
\text { Católica de } \\
\text { Brasília, 2014. }\end{array}$ & $\begin{array}{l}\text { MARCÃO, } \\
\text { Cristina Isabel } \\
\text { Conchinha. } \\
\text { Robots } \\
\text { Necessidades } \\
\text { Educativas } \\
\text { Especiais: O } \\
\text { desenho de uma } \\
\text { oficina de } \\
\text { formação para a } \\
\text { aplicação da } \\
\text { robótica } \\
\text { educativa em } \\
\text { contexto } \\
\text { inclusivo. [tese } \\
\text { de doutorado]. } \\
\text { Universidade } \\
\text { Nova de Lisboa, } \\
\text { Faculdade de } \\
\text { Ciências } \\
\text { Tecnologia, e } \\
\text { 2017. }\end{array}$ & $\begin{array}{l}\text { RODRIGUES, } \\
\text { Sânnya } \\
\text { Fernanda } \\
\text { Nunes. } \\
\text { Metacognição } \\
\text { em práticas } \\
\text { colaborativas } \\
\text { numa } \\
\text { comunidade } \\
\text { de b-learning: } \\
\text { um estudo de } \\
\text { caso. [tese de } \\
\text { doutorado]. } \\
\text { Universidade } \\
\text { de Aveiro, } \\
2014 \text {. }\end{array}$ & $\begin{array}{l}\text { TEIXEIRA, } \\
\text { Jaylson. } \\
\text { Contribuições } \\
\text { para o ensino } \\
\text { de } \\
\text { programação } \\
\text { de } \\
\text { computadores } \\
\text { a futuros } \\
\text { professores de } \\
\text { matemática. } \\
\text { [tese de } \\
\text { doutorado]. } \\
\text { Universidade } \\
\text { do Minho, } \\
\text { 2017. }\end{array}$ \\
\hline
\end{tabular}

Fonte: os autores (2019).

\section{Segunda perspectiva situacional: categorias, universidades e ano de publicação}

Para organização e registro dessa perspectiva, criou-se uma tabela online, (disponível em: https://goo.gl/Vn4CRw), que indica a presença dos descritores no 


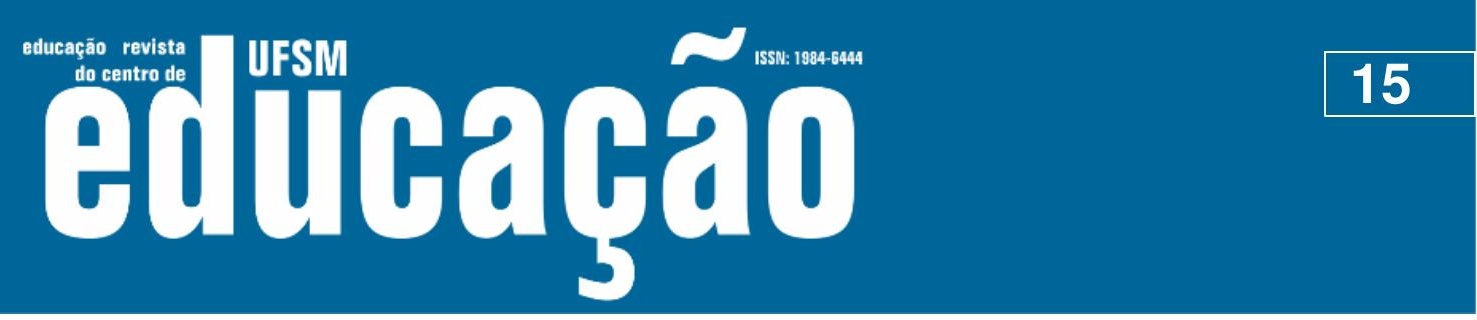

ISSN: 1984-6444 | http://dx.doi.org/10.5902/1984644440698

título $(T)$, nas palavras-chave $(P-C)$ e no resumo $(R)$ das teses, a pergunta de pesquisa, o objetivo geral, os objetivos específicos e a metodologia.

No Quadro 4, resume-se esta tabela online, em que foi sinalizado com um $x$ a presença das categorias gerais e específicas em espaços próprios, no título, nas palavras-chave e no resumo das teses. Em casos específicos, apresentam-se, com um asterisco, conceitos que se relacionam com as categorias de análise e/ou observações que, de alguma forma, possam contribuir para a qualidade da pesquisa. Ainda nesse quadro, expandiu-se a busca pelos descritores em todo o conteúdo das teses e os resultados foram sinalizados em amarelo. Destas, algumas apresentam uma dimensão ampla de conteúdo, que poderá ser considerada no decorrer desta e de futuras pesquisas ${ }^{3}$.

Quadro 4 - Organização e balanço das informações

\begin{tabular}{|c|c|c|c|c|}
\hline $\begin{array}{c}\text { INFORMAÇÕES SOBRE AS } \\
\text { TESES }\end{array}$ & $\mathbf{T}$ & P-C & $\mathbf{R}$ & TERMOS \\
\hline $\begin{array}{l}\text { 1. } \begin{array}{l}\text { Alcântara (2014). UCB. } \\
\text { https://goo.gl/WYnxJG }\end{array} \\
\end{array}$ & $x$ & $x$ & $x$ & $\begin{array}{c}\text { Metacognição *estratégias de } \\
\text { aprendizagem (Item 1.5) }\end{array}$ \\
\hline $\begin{array}{l}\text { 2. } \begin{array}{r}\text { Rosária (2014). USP. } \\
\text { https://goo.gl/82dBuk }\end{array} \\
\end{array}$ & - & - & $x$ & $\begin{array}{l}\text { Metacognição *estratégias } \\
\text { metacognitivas (Item 4.3) }\end{array}$ \\
\hline $\begin{array}{l}\text { 3. Cardoso (2017). UFBA. } \\
\text { https://goo.gl/FAfPeM }\end{array}$ & \multicolumn{3}{|c|}{$\begin{array}{l}\text { * Cognição no sumário } \\
\text { (Cap.3). }\end{array}$} & Cognitive functioning \\
\hline $\begin{array}{lll}\text { 4. } & \begin{array}{l}\text { Viana } \\
\text { https://goo.gl/zcSaQ8 }\end{array} & \text { UFC. } \\
\end{array}$ &.- & - & $\mathrm{x}$ & Metacognição \\
\hline $\begin{array}{l}\text { 5. Silva (2016). } \\
\text { Unesp.https://goo.gl/CLHx9j }\end{array}$ & \multicolumn{3}{|c|}{$\begin{array}{l}\text { * Cognição no sumário } \\
\text { (Cap. 2). }\end{array}$} & Nova cultura da aprendizagem \\
\hline $\begin{array}{l}\text { 6. Fuck (2016). UNISINOS. } \\
\text { https://goo.gl/G4eL3k }\end{array}$ & $\mathrm{x}$ & $x$ & $\mathrm{x}$ & $\begin{array}{c}\text { Programação *scratch (Resumo) e } \\
\text { metacognição (Item 3.2) }\end{array}$ \\
\hline $\begin{array}{l}\text { 7. Machado (2014). UCB. } \\
\text { https://goo.gl/HY76Ua }\end{array}$ & - & - & $x$ & Metacognição \\
\hline 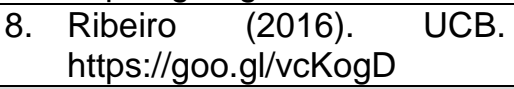 & - & - & $x$ & Metacognição \\
\hline $\begin{array}{l}\text { 9. Silva (2016). UFC. } \\
\text { https://goo.gl/US8yN9 }\end{array}$ & \multicolumn{3}{|c|}{$\begin{array}{l}{ }^{*} \text { Aspectos cognitivos no } \\
\text { sumário (Item 2.4). }\end{array}$} & Cognitive functioning \\
\hline $\begin{array}{l}\text { 10. Souza (2014). USP. } \\
\text { https://goo.gl/nkdMfC }\end{array}$ & \multicolumn{3}{|c|}{$\begin{array}{c}\text { * Metacognição no sumário } \\
\text { (Item 1.1). }\end{array}$} & Metacognition \\
\hline $\begin{array}{l}\text { 11. Barbosa (2017). Unesp. } \\
\text { https://goo.gl/2di9EC }\end{array}$ & \multicolumn{3}{|c|}{$\begin{array}{l}{ }^{*} \text { Metacognição (Itens 2.3, } \\
2.4 \text { e 2.5) }\end{array}$} & Metacognição \\
\hline $\begin{array}{l}\text { 12. Barbosa (2016). UFU. } \\
\text { https://goo.gl/o9fWJE }\end{array}$ & $\mathrm{x}$ & $x$ & $\mathrm{x}$ & $\begin{array}{c}\text { Robótica * programação (Resumo e } \\
\text { sumário) }\end{array}$ \\
\hline $\begin{array}{l}\text { 13. Schivani (2014). USP. } \\
\text { https://goo.gl/hEtgbQ }\end{array}$ & $x$ & $x$ & $x$ & Robótica \\
\hline
\end{tabular}




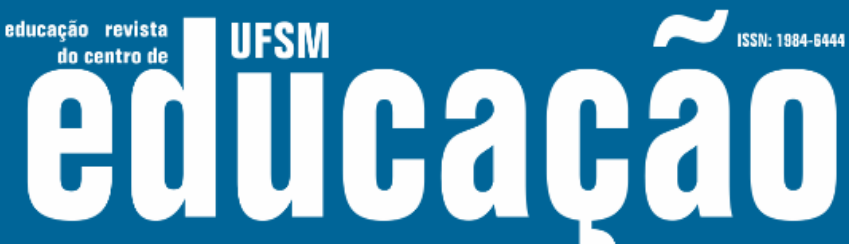

ISSN: 1984-6444 | http://dx.doi.org/10.5902/1984644440698

Continuação Quadro 4 - Organização e balanço das informações

\begin{tabular}{|l|c|c|c|c|}
\hline $\begin{array}{c}\text { INFORMAÇÕES SOBRE AS } \\
\text { TESES }\end{array}$ & T & P-C & R & TERMOS \\
\hline $\begin{array}{c}\text { 14. Dominguez (2014). USP. } \\
\text { https://goo.gl/Kr7JrV }\end{array}$ & \multicolumn{2}{|c|}{ Tese indisponível } & $\mathrm{x}$ & Robótica \\
\hline $\begin{array}{c}\text { 15. Rodrigues (2014). UA. } \\
\text { https://goo.gl/Vzmw8e }\end{array}$ & $\mathrm{x}$ & $\mathrm{x}$ & $\mathrm{x}$ & Metacognição \\
\hline $\begin{array}{c}\text { 16. Marcão (2017). UNL. } \\
\text { https://goo.gl/sNswxJ }\end{array}$ & $\mathrm{x}$ & $\mathrm{x}$ & $\mathrm{x}$ & $\begin{array}{c}\text { Robótica *abordagens } \\
\text { metacognitivas (Item 2.6) }\end{array}$ \\
\hline $\begin{array}{c}\text { 17. Teixeira (2017). UMINHO. } \\
\text { https://goo.gl/9r6xkr }\end{array}$ & $\mathrm{x}$ & - & $\mathrm{x}$ & $\begin{array}{c}\text { Programação *scratch e } \\
\text { metacognição (Sumário e itens } \\
\text { 3.4.1/3.4.3/5.3/5.3.1) }\end{array}$ \\
\hline
\end{tabular}

Fonte: os autores (2019).

Treze teses desse Modelo $I^{4}$ serão consideradas para a sequência da pesquisa. Das categorias específicas, identifica-se que o termo metacognição aparece em onze teses assim identificado: duas no título, resumo e palavras-chave; quatro no resumo; uma no abstract e no sumário; quatro no decorrer do conteúdo. Para o descritor programação de computadores, obteve-se um total de três teses: uma consta no título e no resumo; uma no resumo e no sumário; uma no título, resumo e palavraschave. Para o descritor robótica, há três teses, sendo que em ambas aparece o termo no título, resumo e palavras-chave.

Para as categorias gerais, identificam-se três pesquisas assim distribuídas: duas na categoria programação de computadores, metacognição e scratch, metacognição; uma na categoria robótica, metacognição. As referidas teses estão grifadas em amarelo no quadro anterior e são, respectivamente, de autoria dos pesquisadores Rafael Schilling de Fuck, Cristina Isabel Conchinha Marcão e Jaylson de Teixeira.

Quanto às universidades, seis teses situam-se no Brasil e três em Portugal. No endereço <https://goo.gl/QYvsp5>, há a descrição dessas teses, cuja localização geográfica das universidades nas quais elas foram produzidas está representada na Figura 1. Destas, a UCB apresenta duas teses defendidas em 2014 e uma em 2016. As três contemplam a categoria metacognição. A USP apresenta três teses 


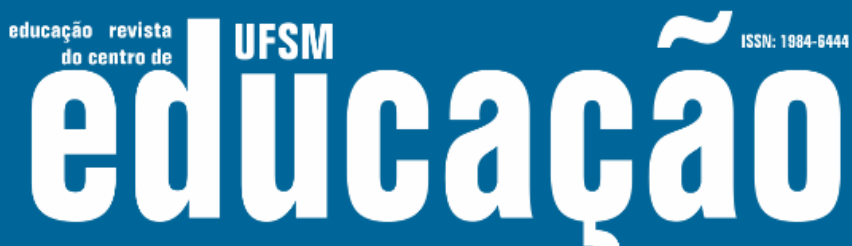

ISSN: 1984-6444 | http://dx.doi.org/10.5902/1984644440698

defendidas em 2014; dentre elas, duas contemplam metacognição e uma robótica. As demais universidades apresentam uma tese cada.

Figura 1 - Distribuição das teses por instituição

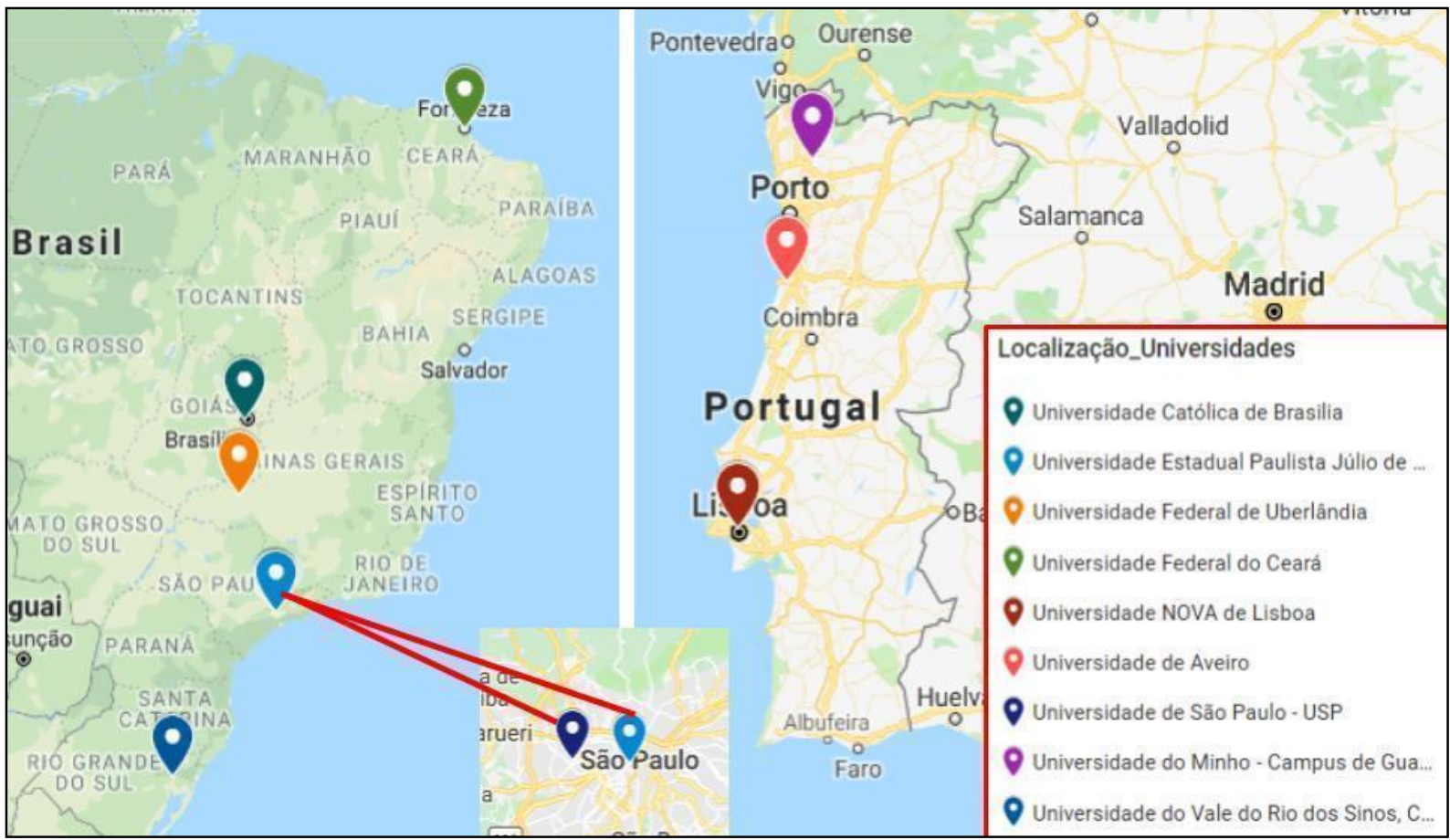

Fonte: elaboração dos autores (2019) através do Google Maps.

Diante desse balanço, analisa-se o conhecimento elaborado do ponto de vista teórico e metodológico. Segundo Romanowski (2002, p. 14), esse momento da pesquisa vai localizar as lacunas existentes para então chegar a subsídios norteadores do problema de pesquisa. Com isso, pode-se ter maior segurança na caminhada, conforme mencionado na introdução desta investigação.

\section{Modelo II: referenciais teóricos e metodológicos sobre as pesquisas encontradas}

Com base na exposição feita no início do tópico, em Ferreira (2002) e Morosini (2015), segue-se para a segunda dimensão destaque sobre os temas que se deseja investigar. Assim, objetiva-se expor os referenciais teóricos e aspectos metodológicos 


\section{Autนaดูลิ}

ISSN: 1984-6444 | http://dx.doi.org/10.5902/1984644440698

mais citados nas 13 pesquisas encontradas. Para isso, seguem-se algumas estratégias: em uma tabela online, listaram-se os títulos e/ou subtítulos das teses que apresentassem as categorias de análise e relacionaram-se os referenciais teóricos mais utilizados; em outra tabela, verificaram-se os referenciais que se repetiam entre as teses. Por fim, chegou-se a um resultado, sintetizado na Figura 2.

Figura 2 - Amostra da II dimensão destaque por meio dos referenciais teóricos

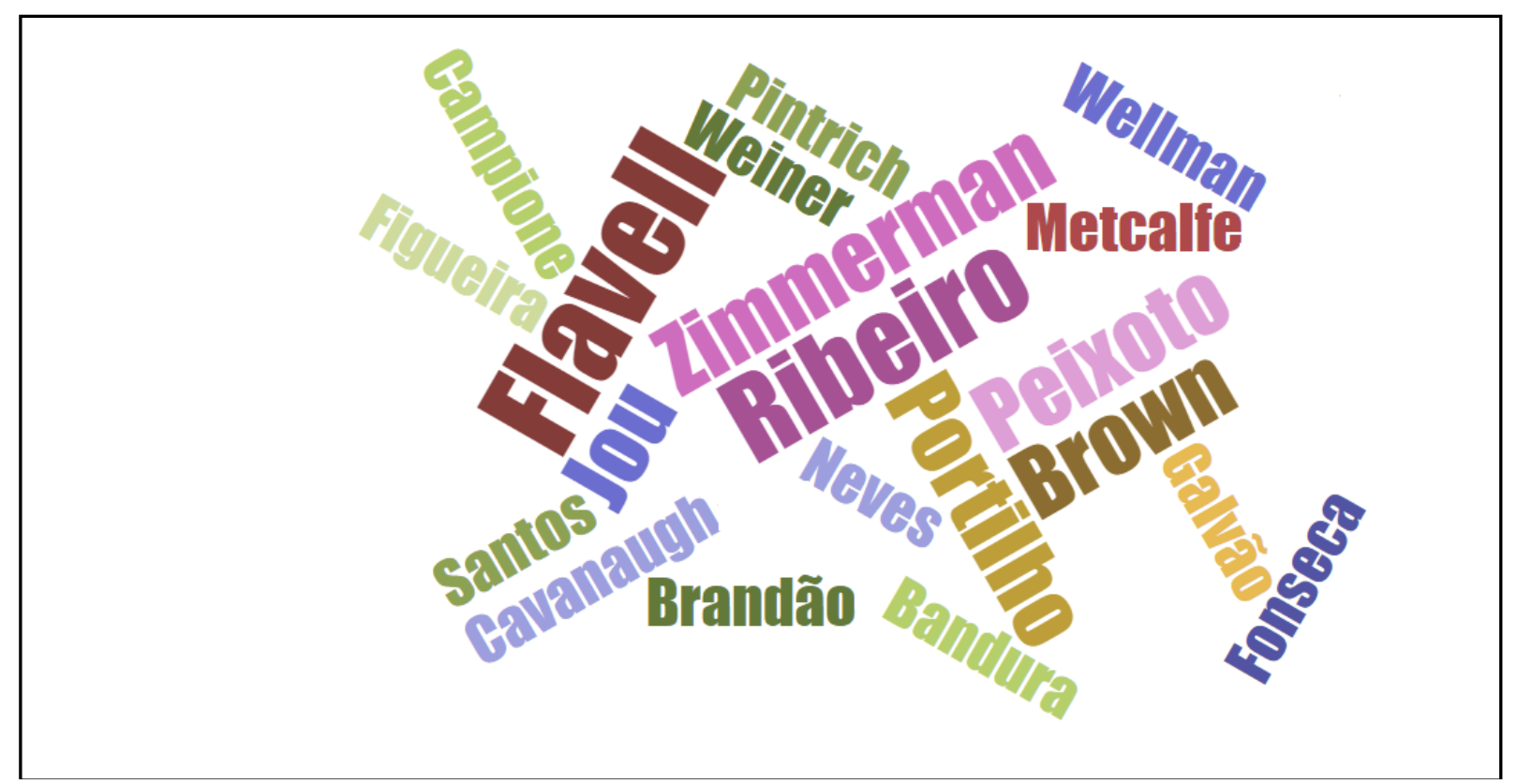

Fonte: elaboração dos autores (2019) por meio de Word Cloud Generator ${ }^{5}$.

$\mathrm{Na}$ nuvem de palavras apresentada na Figura 2 foram digitados os autores mais citados nas teses analisadas e que subsidiaram as discussões em torno da metacognição, como mencionado anteriormente. Para a construção dessa nuvem, foram computados no programa o sobrenome do autor tantas vezes quantas foram as teses em que ele se apresentou como referencial teórico no que diz respeito à metacognição. Por exemplo, John H. Flavell foi anotado como Flavell cinco vezes, uma vez que ele embasou as discussões em cinco das oito teses analisadas.

O resultado da nuvem de palavras identifica que Flavell é um dos mais utilizados nas teses, o que corrobora com os achados de Zohar e Barzilai (2013), ao apontarem que esse autor tem subsidiado os estudos envolvendo metacognição nos 


\section{W usm etituará

ISSN: 1984-6444 | http://dx.doi.org/10.5902/1984644440698

processos educativos. Ele é seguido de Barry Zimmerman, que tem enfatizado a parte da autorregulação como elemento principal da aprendizagem envolvendo a metacognição. Célia Ribeiro é outra autora que tem sido referenciada nos estudos de metacognição, particularmente por ter sido uma das pioneiras no Brasil a utilizar o termo.

Dentre as pesquisas que apresentaram os descritores programação de computadores e robótica, considera-se Seymour Papert a referência mais citada e utilizada para embasamento teórico. O autor é referenciado em cinco das seis teses que tratam deste termo. Segundo Soares e Maciel (2000), somente a partir de uma pesquisa de caráter bibliográfico, objetivando-se a sistematização das produções em determinada área, é que se oportuniza a plena compreensão do estado em que se encontra o conhecimento em sua amplitude, seja nas tendências teóricas, seja nas vertentes metodológicas. Evidencia-se que, segundo as autoras, a busca por essa compreensão sobre determinado tema é necessária para o processo de evolução da ciência.

Assim, apresenta-se, no próximo quadro, a estratégia utilizada para chegar à segunda dimensão, termo conceituado por Ferreira (2002), ou vertente, conforme Soares e Maciel (2000). Para melhor compreender as formas e as condições em que as teses foram produzidas metodologicamente, registrou-se detalhadamente em (http://bit.do/fKH8i), na segunda coluna, a metodologia e os instrumentos utilizados para a coleta de dados e, na terceira coluna, o público e local, uma vez que todas utilizaram a pesquisa de campo.

Quadro 5 - Amostra da II dimensão destaque por meio dos referenciais metodológicos

\begin{tabular}{|l|l|l|}
\hline No TESE & METODOLOGIA/ INSTRUMENTOS & \multicolumn{1}{|c|}{ AMOSTRAGEM/ LOCAL } \\
\hline \multirow{3}{*}{ TESE 1 } & $\begin{array}{l}\text { Pesquisa empírica quali-quantitativa. } \\
\text { Instrumentos: formulação, aplicação e e } \\
\text { análise de dois questionários. } \\
\text { Realização de uma intervenção, } \\
\text { seguida de entrevistas } \\
\text { semiestruturadas. }\end{array}$ & $\begin{array}{l}\text { Sujeitos/perfil: } 982 \text { alunos responderam ao } \\
\text { questionário. Uma amostra foi recolhida em duas } \\
\text { universidades, com 355 alunos, 109 (37,7\%) } \\
\text { pertencentes a uma universidade pública e 627 } \\
\text { alunos (62,3\%) pertencentes a uma universidade } \\
\text { privada. Local: Ensino Superior / Distrito Federal. }\end{array}$ \\
\hline
\end{tabular}

Fonte: os autores (2019) 


\section{Autตaดูão}

ISSN: 1984-6444 | http://dx.doi.org/10.5902/1984644440698

Considera-se que a metodologia utilizada nas produções encontradas é, em sua maioria, qualitativa e que abordam diferentes perspectivas teórico-metodológicas como referencial. Em suas especificidades, duas fundamentam-se em uma abordagem epistemológica; uma é fenomenológica; três realizam estudo de investigação quali-quantitativa; duas apoiam-se em estudo de caso. As demais seguem, em suas singularidades, uma perspectiva quase experimental; pesquisaação; normativa, metacognitiva e contextual6; e com base na teoria antropológica do didático ${ }^{7}$.

Ainda que se perceba a variedade metodológica entre as teses, ressalta-se a utilização de apenas dois instrumentos de coleta de dados: a entrevista, que aparece em dez teses, e o questionário que integra oito estudos. Sobre a diferença entre os dois instrumentos e a escolha sobre entrevistas em detrimento do questionário, Alcântara (2014, p. 123) afirma que, apesar da eficácia do questionário "para fornecer os dados quantitativos, não é adequado para acessar as percepções mais profundas dos estudantes". Tal identificação justifica a escolha das entrevistas pela maioria das pesquisas analisadas, especialmente as que retratam estudos envolvendo processo de intervenção didática, como as de Alcântara (2014), de Viana (2016) e de Fuck (2016).

Sobre a pesquisa de campo, Bogdan e Biklen (1991, p. 150), como citado por Barbosa (2016, p. 84), defendem que "é típico que o investigador escreva, de preferência num processador de texto ou computador, o que aconteceu. Ele ou ela dão uma descrição das pessoas, objetos, lugares, acontecimentos, atividades e conversas". Essa forma de registro das informações faz relação com o exposto anteriormente por Morosini (2015): a pesquisa é uma tarefa de autoria que, quando exercitada de forma proativa e com autonomia, fortalece o alcance do sucesso.

Quanto à quantidade de participantes, Rosa e Arnoldi (2009), citados por Souza (2014, p. 51-52), mencionam que "não é o número de participantes que proporciona dados relevantes ao pesquisador, mas o significado e a importância desses dados para a realização da investigação proposta". Salienta-se que as quantidades máximas de sujeitos envolvidos nas produções encontradas foram de 


\section{Autนaดูลิ}

ISSN: 1984-6444 | http://dx.doi.org/10.5902/1984644440698

982, 649 e 106 e a menor quantidade foi 3. Nas demais teses, o número de sujeitos participantes variou entre 6 e 26 sujeitos.

Ainda sobre o público, oito teses envolveram somente alunos, duas somente professores, duas envolveram alunos e professores e uma tese apresentou outro tipo de público de várias áreas além da educacional. Quanto ao local, seis teses direcionaram-se ao ensino superior, seis à educação básica e uma para diferentes lugares do Brasil e do exterior e para diversos campos de atuação. Baseando-se nisso, evidencia-se que a maioria das pesquisas envolveu alunos - de educação básica e superior.

Os resultados expostos até aqui destacam as dimensões teóricas e metodológicas e revelam-se importantes para a construção de estudos futuros vinculados aos temas investigados. Entretanto, como forma de aprofundamento, a próxima seção ocupa-se de discutir as teses que apresentaram as categorias gerais de análise. Trata-se das teses sinalizadas em amarelo no Quadro 4.

\section{Mapeamento que permitirá continuar a caminhada}

A tese de Fuck (2016) tem como título Da recognição e da cognição inventiva: uma cartografia das experiências de programação por estudantes de escolas públicas do ensino fundamental. A tese de Marcão (2017) intitula-se Robots \& necessidades educativas especiais: o desenho de uma oficina de formação para a aplicação da robótica educativa em contexto inclusivo. A tese de Teixeira (2017) designa-se Contribuições para o ensino de programação de computadores a futuros professores de Matemática. Para apresentá-las, selecionam-se, como objeto de discussão, quatro dimensões dos referidos estudos, a saber: problema, objetivo geral, resultado e fragilidade, apresentadas, nessa ordem, no Quadro 6: 


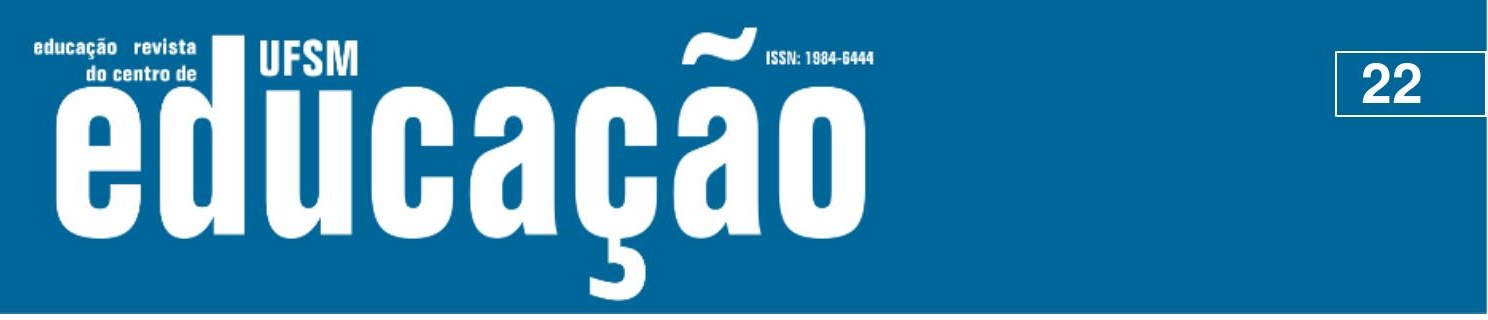

ISSN: 1984-6444 | http://dx.doi.org/10.5902/1984644440698

Quadro 6 - Comparação entre as teses resultantes

\begin{tabular}{|c|c|c|}
\hline FUCK (2016) & MARCÃO (2017) & TEIXEIRA (2017) \\
\hline $\begin{array}{lr}\text { Como } & \text { se } \\
\text { constituem } & \text { os } \\
\text { processos } & \\
\text { cognitivos } & \\
\text { emergentes } & \text { da } \\
\text { experiência } & \text { de } \\
\text { programação } & \text { de } \\
\text { alunos monitores? }\end{array}$ & $\begin{array}{l}\text { Qual o desenho adequado de uma oficina de } \\
\text { formação de professores que capacite os docentes } \\
\text { para a utilização da robótica educativa em contexto } \\
\text { inclusivo? }\end{array}$ & $\begin{array}{l}\text { Como conduzir um processo } \\
\text { de aprendizagem em salas } \\
\text { regulares de programação de } \\
\text { computadores, de modo a } \\
\text { contribuir para o } \\
\text { desenvolvimento do } \\
\text { pensamento computacional } \\
\text { na formação de futuros } \\
\text { professores de matemática? }\end{array}$ \\
\hline \begin{tabular}{lr} 
Construir & uma \\
cartografia & dos \\
processos & \\
cognitivos & de \\
alunos, os & quais \\
emergem de suas \\
experiências de \\
\multicolumn{2}{l}{ programação }
\end{tabular} & $\begin{array}{l}\text { Desenhar, testar e aperfeiçoar um modelo de } \\
\text { oficina de formação sobre a Robótica Educativa } \\
\text { (RE) aplicada às Necessidades Educativas } \\
\text { Especiais (NEE), em uma abordagem } \\
\text { metodológica mista, de carácter exploratório e } \\
\text { assente na Design-Based Research. }\end{array}$ & $\begin{array}{l}\text { Avaliar práticas adotadas } \\
\text { para promover o pensamento } \\
\text { computacional em um } \\
\text { ambiente de aprendizagem } \\
\text { para futuros professores de } \\
\text { Matemática. }\end{array}$ \\
\hline $\begin{array}{l}\text { A constituição de } \\
\text { pistas acerca dos } \\
\text { processos } \\
\text { cognitivos } \\
\text { emergentes das } \\
\text { experiências de } \\
\text { programação dos } \\
\text { sujeitos. De modo } \\
\text { geral, vislumbrou- } \\
\text { se que essas } \\
\text { experiências } \\
\text { foram, } \\
\text { predominantemen } \\
\text { te, recognitivas. }\end{array}$ & $\begin{array}{l}\text { Os resultados obtidos permitiram compreender o } \\
\text { conceito dos professores sobre robótica educativa, } \\
\text { fazer o levantamento das necessidades } \\
\text { educativas nessa área e desenvolver um modelo } \\
\text { de oficina de formação de professores que } \\
\text { pudesse ser replicado e correspondesse à } \\
\text { necessidade de formação dos docentes nessa } \\
\text { área aplicada às necessidades educativas } \\
\text { especiais. }\end{array}$ & $\begin{array}{l}\text { Entre os resultados, destaca- } \\
\text { se a necessidade de as } \\
\text { escolas e universidades } \\
\text { incentivarem a autonomia e a } \\
\text { criatividade. O resultado } \\
\text { aponta também contribuições } \\
\text { para a metacognição e a } \\
\text { colaboração, uma vez que os } \\
\text { alunos se comparam a seus } \\
\text { colegas ao ajudar e serem } \\
\text { ajudados. }\end{array}$ \\
\hline $\begin{array}{l}\text { São necessárias } \\
\text { intervenções que } \\
\text { promovam } \\
\text { processos } \\
\text { recorrentes de } \\
\text { problematização, } \\
\text { a fim de provocar } \\
\text { rachaduras na } \\
\text { cognição dos } \\
\text { sujeitos, levando- } \\
\text { os à invenção de } \\
\text { si, do } \\
\text { conhecimento e } \\
\text { do mundo. }\end{array}$ & $\begin{array}{l}\text { Sugere que, em oficinas com objetivos similares, o } \\
\text { desenho ideal seja estimular a participação } \\
\text { informal entre os participantes e reduzir o número } \\
\text { de desistências, mas, sobretudo, } \\
\text { [...] que os formandos adquiram as aprendizagens } \\
\text { necessárias e a autoconfiança para que consigam } \\
\text { criar as suas próprias atividades, de acordo com } \\
\text { as especificidades das suas turmas e dos seus } \\
\text { alunos, e transmitir essas novas aprendizagens, } \\
\text { aumentando assim a autoestima, a proeficiencia } \\
\text { [sic], a autonomia, os conhecimentos e a inclusão } \\
\text { de todos os alunos. (MARCÃO, 2017, p. 278). } \\
\text { Além disso, a autora afirma que, "ao desenhar uma } \\
\text { oficina de formação nesses moldes, que inclua } \\
\text { professores de nacionalidades distintas, devem-se } \\
\text { considerar os conhecimentos dos docentes e os } \\
\text { recursos existentes nos estabelecimentos de } \\
\text { ensino" (MARCÃO, 2017, p. 279). }\end{array}$ & $\begin{array}{l}\text { O autor enfatiza "a relativa } \\
\text { autonomia, uma vez que o } \\
\text { aluno deve contar com o } \\
\text { professor e seus colegas } \\
\text { para superar dificuldades, } \\
\text { fazendo parte da sua } \\
\text { autonomia, a metacognição } \\
\text { que o faz reconhecer suas } \\
\text { limitações, isolar o problema } \\
\text { e procurar ajuda quando } \\
\text { necessário" (TEIXEIRA, } \\
2017, \text { p. 27). }\end{array}$ \\
\hline
\end{tabular}

Fonte: os autores (2019). 


\section{Althaห̧ão}

ISSN: 1984-6444 | http://dx.doi.org/10.5902/1984644440698

As sugestões expostas nessas teses podem ser resumidas da seguinte forma: Fuck (2016) possibilita uma continuidade de seu trabalho, afirmando a necessidade de intervenções sobre os processos recorrentes de problematização. Logo, essas intervenções vêm a promover rachaduras na cognição dos participantes de tais processos. Marcão (2017), por sua vez, sugere que, em oficina de formação que propicie objetivos similares aos seus, além de incentivar a participação informal dos professores e a persistência na proposta até o final, os formandos criem suas próprias atividades e as transmitam aos alunos. Também, que se considere, ainda no início da pesquisa, o conhecimento prévio dos participantes e os recursos existentes nos estabelecimentos de ensino. Por fim, Teixeira (2017) percebe a necessidade de incentivar a autonomia e a criatividade tanto em escolas quanto em universidades e deixa como sugestão de pesquisa um trabalho metacognitivo de fazer com que os sujeitos reconheçam suas próprias limitações e procurem por ajuda quando necessário, mas que saibam isolar seus problemas com autonomia.

Considera-se que essas três fragilidades podem servir de referência para novos estudos, o que vem ao encontro do proposto nesta revisão na forma de estado do conhecimento. Contudo, novos estudos precisam ter clareza do que já foi produzido e de que forma os resultados foram analisados e contribuirão para a qualificação dos processos educativos. Nesse contexto, ao conduzir-se para as considerações, reforça-se o mencionado por Morosini (2015, p. 114), de que é "o sujeito pesquisador quem assume o compromisso com a sua reflexão crítica, com a construção de seu objeto e com a inserção no campo científico".

\section{Considerações finais}

Fundamentando-se em uma abordagem de ruptura dos pré-conceitos e balanço das informações entre 13 pesquisas resultantes desse processo, para uma análise de teses em língua portuguesa com foco em aspectos teóricos e práticos da metacognição, da programação de computadores e da robótica, chega-se a algumas considerações. Cada pesquisa utilizou metodologias qualitativamente díspares, até mesmo algumas desconhecidas em um âmbito científico usual. Contudo, os 


\section{N

ISSN: 1984-6444 | http://dx.doi.org/10.5902/1984644440698

ZOHAR, Anat; BARZILAI, Sarit. A review of research on metacognition in science education: current and future directions. Studies in Science Education, v. 49, n. 2, p.121-169, 252013.2 Disponível em: https://www.tandfonline.com/doi/abs/10.1080/03057267.2013.847261. Acesso em: 14 nov. 2018.

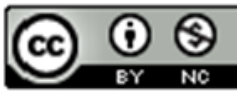

This work is licensed under a Creative Commons Attribution-NonCommercial 4.0 International (CC BY-NC 4.0)

\section{Notas}

\footnotetext{
${ }^{1}$ RCAAP está disponível em: <https://www.rcaap.pt/>. O Repositório oferece o acesso aberto ao conhecimento sobre a produção científica nacional em Portugal, artigos de revistas científicas, comunicações em conferências, relatórios técnicos, teses e documentos de trabalho. O B-On, disponível em: <http://www.b-on.pt/>, é uma ferramenta que facilita o acesso a informações científicas de editoras participantes do consórcio B-on, dentre elas, artigos, monografias, obras de referência, teses e dissertações.
}

${ }^{2}$ Ressalta-se que os descritores de número 2 e 10 metacognition e robótica + metacognição foram suprimidos, pois obtiveram-se os mesmos resultados de teses utilizando-se o descritor metacognição e robótica, metacognição.

${ }^{3}$ Exemplifica-se, a partir da tese de número 17, que não constam os descritores nas palavras-chave, mas apresenta um vasto conteúdo em seu desenvolvimento.

${ }^{4}$ Das 57 teses, as de número 3, 5, 9, 10 e 16 não se repetem entre os sites de busca. As demais pesquisas aparecem entre 2 e 7 vezes no decorrer do processo. As de número 10 e 16 serão consideradas para o mapeamento e as demais, sinalizadas em cinza, serão desconsideradas por inexistir a presença das categorias. As teses de número 3 , 5 e 9 não apresentam as categorias no título, nas palavras-chave e no resumo, mas apresentam assuntos próximos às categorias.

${ }^{5}$ Disponível em: https://www.jasondavies.com/wordcloud/.

${ }^{6}$ Souza (2014) apresenta e discute as vantagens e desvantagens dessas três abordagens de metodologia de pesquisa a partir de concepções adotadas para crenças, métodos de investigação e relação das crenças e das ações. Mais informações em: Souza (2014, p. 43).

7 “A Teoria Antropológica do Didático (TAD), a qual permite modelar o conhecimento por meio de uma Organização Praxeológica (OP) e analisar processos de estudo através dos Momentos Didáticos”. (SCHIVANI, 2014, p. 15). 